Purdue University

Purdue e-Pubs

11-17-2004

\title{
Detection of bacterial cells and antibodies using surface micromachined thin silicon cantilever resonators
}

Demir Akin

Purdue University, demirakin@gmail.com

Amit Gupta

Purdue University, acgupta@purdue.edu

Rashid Bashir

Birck Nanotechnology Center and Bindley Bioscience Center, Purdue University, bashir@purdue.edu

Follow this and additional works at: http://docs.lib.purdue.edu/nanodocs

Akin, Demir; Gupta, Amit; and Bashir, Rashid, "Detection of bacterial cells and antibodies using surface micromachined thin silicon cantilever resonators" (2004). Other Nanotechnology Publications. Paper 1.

http://docs.lib.purdue.edu/nanodocs/1

This document has been made available through Purdue e-Pubs, a service of the Purdue University Libraries. Please contact epubs@purdue.edu for additional information. 


\title{
Detection of bacterial cells and antibodies using surface micromachined thin silicon cantilever resonators
}

\author{
Amit Gupta and Demir Akin \\ Laboratory of Integrated Biomedical Micro/Nanotechnology and Applications, School of Electrical \\ and Computer Engineering, Purdue University, West Lafayette, Indiana 47907-1285 \\ Rashid Bashir ${ }^{\mathrm{a})}$ \\ Laboratory of Integrated Biomedical Micro/Nanotechnology and Applications, School of Electrical \\ and Computer Engineering, Department of Biomedical Engineering, Purdue University, \\ West Lafayette, Indiana 47907-1285
}

(Received 23 March 2004; accepted 4 October 2004; published 17 November 2004)

\begin{abstract}
This article describes a surface micromachined cantilever beam-based resonator for biological sensing applications. The study used a novel microfabrication technique of merged epitaxial lateral overgrowth (MELO) and chemical mechanical polishing (CMP) to fabricate thin, low stress, single-crystal silicon cantilever beams. The vibration spectra of the cantilever beams, excited by thermal and ambient noise, was measured in air using a Dimension 3100 Series scanning probe microscope (SPM), and in certain cases, a Polytec MSV300 laser Doppler vibrometer. The sensors were used to detect the mass of Listeria innocua bacteria by applying increasing concentration of bacteria suspension on the same cantilever beams and measuring the resonant frequency changes in air. Cantilever beams were also used to detect the mass of proteins such as Bovine Serum Albumin (BSA) and antibodies for Listeria that were attached to the cantilever's surfaces by physical adsorption; following which they were used to capture and detect the mass of the bacterial cells on the functionalized cantilever beam surfaces'. The effects of critical point drying of the proteins were evaluated and the results indicate that the functionality of the antibodies was not reduced once rehydrated after critical point drying. The developed biosensor is capable of rapid and ultrasensitive detection of bacteria and promises significant potential for the enhancement of microbiological research and diagnostics. (C) 2004 American Vacuum Society. [DOI: 10.1116/1.1824047]
\end{abstract}

\section{INTRODUCTION}

Cantilever beams were introduced to nanotechnology with their use as probes in atomic force microscopy (AFM). ${ }^{1}$ Cantilever beams can be considered as a link between the physical realms in the microscale and the nanoscale regimes. They have attracted a lot of attention in the microelectromechanical systems (MEMS) and nanotechnology community due to their simple structure and fabrication process flow, along with their displayed versatility in a wide range of applications as sensors and actuators. ${ }^{2}$ Microscale cantilever beambased resonators have been shown to be extremely sensitive biosensors. ${ }^{3,4}$ The change in resonant frequency of the cantilever beam, due to mass change after analyte binding, is used as the detection scheme. This technique can fundamentally be used to detect single bacterial cells. ${ }^{5}$ The advantage of this method over traditional diagnosis systems such as Enzyme-Linked Immunosorbent Assay (ELISA) (Ref. 6) or oligonucleotide (DNA or RNA) (Ref. 7) based assays is that whole, intact bacterial cells are detected. Hence, the present method can be not only ultrasensitive but can also be a less time consuming and a more energy efficient process. Functionalizing of arrays of cantilever beams with receptors to different analytes can also allow for the detection of multiple agents on the same chip.

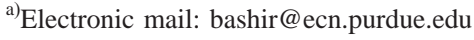

Silicon microfabrication technology has many advantages which include: (i) precise control of dimensions, (ii) miniaturization of devices, (iii) fabrication of an array of devices with very close physical parameter values, (iv) batch fabrication leading to decrease in production cost, and (v) possibility of integration of various functional devices on the same platform leading to the ultimate goal of a "lab-on-achip." Single crystal materials such as silicon are preferred materials to make sensor elements due to their high mechanical quality factor. ${ }^{8}$

The purpose of this article is to present the use of a surface micromachined silicon cantilever beam as a resonant biosensor for the detection of mass of bacterial cells and antibodies. In the present study, nonspecific binding of bacterial cells on cantilever beams was carried out in order to measure the effective dry mass of the Listeria innocua bacteria. The mass of antibody layer was also measured in order to demonstrate the sensitivity of the cantilever beams to the mass of the protein layers and to demonstrate antigenantibody interactions of bacterial cells adhering to functionalized surfaces more efficiently than on nonfunctionalized (bare) surfaces. Critical point drying (CPD) was performed before every step of measurement of the resonant frequencies in air, in order to avoid stiction. The functionality of the antibodies after CPD was qualitatively evaluated in the present study in order to the gauge their effectiveness. 


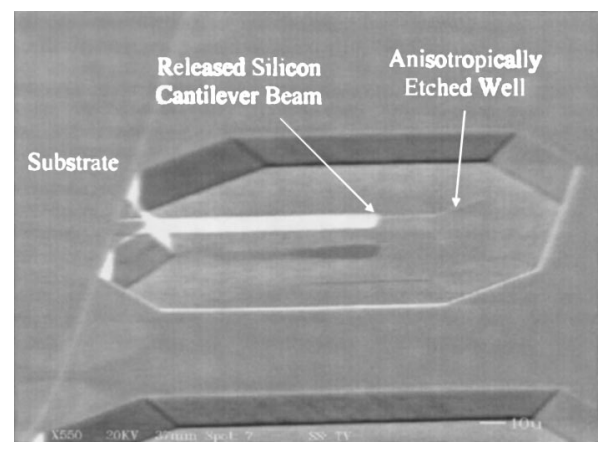

FIG. 1. SEM micrographs of a released rectangular shaped cantilever beam.

\section{MATERIALS AND METHODS}

\section{A. Cantilever beam fabrication and mechanical characterization}

A novel fabrication technique was developed to fabricate thin, low-stress, single-crystal cantilever beams. ${ }^{9}$ The process flow involves using merged epitaxial lateral overgrowth (MELO) and chemical mechanical polishing (CMP) of single crystal silicon. MELO can be regarded as an extension of selective epitaxial growth (SEG) and epitaxial lateral overgrowth (ELO). Descriptions of the various forms of selective silicon growth have been reported previously. ${ }^{10,11}$ Figure 1 shows a scanning electron micrograph of a rectangular shaped cantilever beam obtained using the present process flow. Among the previous works that have reported on the fabrication of ultrathin cantilever beams, virtually all of them employ a SOI wafer as the starting material. ${ }^{12,13}$ The fabrication method used in this study has the advantage of fabricating all-silicon structures without any oxide layer being present under the silicon anchor of the cantilever beam. This eliminates any mismatch in material properties between the silicon and silicon dioxide material that exists when using SOI as the starting material. This in turn eliminates, or certainly decreases, the residual stresses in cantilever beams that are a source of vibrational energy loss. ${ }^{8}$ The present fabrication method also has the potential of fabricating arrays of cantilever beams with varying length, width, and thickness dimensions on the same substrate. This can allow the fabrication of arrays of cantilever beams with a range of mechanical resonant frequencies and sensitivities. The current fabrication method can be extended to confined lateral epitaxy or tunnel epitaxy to fabricate nanoscale thick cantilever beams for ultrasensitive-detection applications.

Thermal and ambient noise was used to excite the cantilever beams and their corresponding vibration spectra was measured in air using a Dimension 3100 Series (Digital Instruments, Veeco Metrology Group, Santa Barbara, CA) scanning probe microscope (SPM) and in certain experiments a MSV300 (Polytec PI, Auburn, MA) laser Doppler vibrometer (LDV). Thermal noise excitation was used since it does not require any power and it does not excite other stiffer, higher mechanical resonance modes such as that of the cantilever holder. The advantage of externally driving the cantilever beam will be of course more sensitive mass detec-
TABLE I. Planar dimensions and measured values of unloaded resonant frequency, quality factor, spring constant, and mass sensitivity.

\begin{tabular}{cccccc}
\hline \hline $\begin{array}{c}\text { Cantilever } \\
\text { designation }\end{array}$ & $\begin{array}{c}\text { Length and } \\
\text { width }(\boldsymbol{\mu m})\end{array}$ & $\begin{array}{c}\text { Resonant } \\
\text { frequency } \\
(\mathbf{k H z})\end{array}$ & $\begin{array}{c}\text { Quality } \\
\text { factor, } Q\end{array}$ & $\begin{array}{c}\text { Spring } \\
\text { constant } \\
(\mathbf{N} / \mathbf{m})\end{array}$ & $\begin{array}{c}\text { Mass } \\
\text { sensitivity } \\
(\mathbf{H z} / \mathbf{p g})\end{array}$ \\
\hline 1 & $L=78 W=23$ & 85.6 & 56 & 0.145 & 65 \\
2 & $L=79 W=24$ & 80.7 & 54 & 0.097 & 90 \\
\hline \hline
\end{tabular}

tion by achieving a higher quality factor, as described below. The vertical deflection signal of the cantilever beam was extracted from the SPM using a Digital Instrument Signal Access Module (SAM) and then digitized. The power spectral density was then evaluated using MATLAB software. The thermal vibration spectra data was fit (using the least square method) to the amplitude response of a simple harmonic oscillator (SHO) in order to obtain the resonant frequency and the quality factor. The amplitude response of a SHO is given as $^{14}$

$$
A(f)=A_{\mathrm{dc}} \frac{f_{0}^{2}}{\sqrt{\left[\left(f_{0}^{2}-f^{2}\right)^{2}+\frac{f_{0}^{2} f^{2}}{Q^{2}}\right]}},
$$

where $f$ is the frequency in $\mathrm{Hz}, f_{0}$ is the resonant frequency, $Q$ is the quality factor, and $A_{\mathrm{dc}}$ is the cantilever amplitude at zero frequency. All the reported values of resonant frequency and quality factor presented and used in this work are those that have been obtained by curve fitting. The cantilever beams were calibrated by measuring their spring constant using the added mass method. ${ }^{15}$ Table I shows the planar dimensions and mechanical characterization results for specifically two cantilever beams, designated cantilever 1 , and cantilever 2, which have been used in this study. Different resonant frequency and spring constant was measured for different cantilever beams with around the same planar dimensions due to difference in thickness of these cantilevers. Based on the mechanical parameters of the cantilever beams, it is possible to determine the minimum detectable frequency change $\Delta f_{\min }$, which is limited by thermal noise, ${ }^{16,17}$ as given below:

$$
\Delta f_{\min }=\frac{1}{A} \sqrt{\frac{f_{0} k_{B} T B}{2 \pi k Q}},
$$

where $A$ is the square root of the mean-square amplitude of the cantilever beam, $k_{B}$ is Boltzmann's constant, $T$ is the temperature, $f_{0}$ is the resonant frequency, $k$ is the spring constant, and $B$ is the measurement bandwidth. This is calculated to be around $150-200 \mathrm{~Hz}$ for the cantilever beams used in this study. It can be seen that externally driving the cantilever beam will lead to an increase in the amplitude and the quality factor, resulting in the decrease of the minimum detectable frequency shift, leading to an improvement in the mass detection sensitivity. 


\section{B. Bacterial growth conditions and chemical reagents used}

Listeria innocua bacteria were grown in Luria-Bertani (LB) broth at $37^{\circ} \mathrm{C}$ placed in an incubator. The initial concentration of the bacterial suspension was estimated to be around $5 \times 10^{8}$ cells $/ \mathrm{ml}$. The buffer used in all the experiments in the present study was phosphate buffered saline (PBS) with $p \mathrm{H} 7.4(137 \mathrm{mM} \mathrm{NaCl}, 2.7 \mathrm{mM} \mathrm{KCl}$ and $10 \mathrm{mM}$ phosphate buffer solution). The bacteria were transferred to the PBS buffer for further dilution. Bacterial suspensions in concentration varying from $5 \times 10^{6}$ to $5 \times 10^{8}$ cells $/ \mathrm{ml}$ were introduced on the cantilever beam surfaces. Goat affinitypurified polyclonal antibody for Listeria innocua was used (Kirkegaard \& Perry Laboratories, Gaithersburg, MD). BSA (Bovine Serum Albumin) was used as a blocking agent in order to prevent nonspecific binding of bacteria cells in areas not covered by the antibody layer. ${ }^{18}$ Tween- $20(0.05 \%$ by volume) in PBS was used as a surfactant in order to remove the loosely bound bacteria attached to the surfaces.

\section{Dry mass measurement of bacterial cells}

Nonspecific binding of bacteria was performed on the cantilever beam surfaces in order to obtain the effective dry mass of Listeria innocua bacteria. All the resonant frequency measurements in the present study were done in air. The measurements were performed using a laser Doppler vibrometer due to resources constraints. In order to prevent stiction of the cantilever structures onto the underlying substrate after removal from liquid, the structures were dried using critical point drying (CPD). Following the introduction of the bacterial suspension over the cantilever beam for thirty minutes, the cantilever beams were immersed in ethanol and dried using CPD. The above procedure was repeated on the same cantilever beams with increasing bacteria concentration in order to get frequency shift as a function of cell number bound to the cantilever. The number of bacteria on the cantilever was counted using a dark-field microscope and doubled to account for the bacteria bound at the bottom of the cantilever.

\section{Antibody coating of cantilever beams}

BSA and the antibody to Listeria innocua bacteria were immobilized on the cantilever beam surface using physical adsorption. Both BSA and the antibody solution were introduced on the cantilever beams by dispensing $10-15 \mu \mathrm{l}$ of the solutions using micropipettes over the cantilever beam locations on the chip.

The cantilever beams were first cleaned using piranha solution $\left(\mathrm{H}_{2} \mathrm{O}_{2}: \mathrm{H}_{2} \mathrm{SO}_{4}=1: 1\right)$ and then immersed in ethanol before being critical point dried. The resonant frequency was measured in order to obtain the unloaded resonant frequency. The cantilevers were immersed in the Listeria antibody, at a concentration of $1 \mathrm{mg} / \mathrm{ml}$, for $15 \mathrm{~min}$. The cantilevers were then rinsed for around $30 \mathrm{~s}$ in deionized (DI) water and treated with BSA, at a concentration of $2 \mathrm{mg} / \mathrm{ml}$, for $15 \mathrm{~min}$. Then the samples were again rinsed in DI for around $30 \mathrm{~s}$ and then treated in increasing concentrations of methanol in PBS ranging from $1 \%$ to $100 \%$. Finally, placing the cantilevers in a $100 \%$ methanol solution, they were dried using critical point drying. The resonant frequency of the cantilever beam was then measured in air in order to get the change in frequency due to the antibody and BSA mass.

The antibody-coated cantilevers were treated in PBS buffer for $15 \mathrm{~min}$ (in order to rehydrate the antibodies) followed by a short rinse of around $5 \mathrm{~s}$ in DI. The cantilevers were then treated with a bacterial suspension of Listeria innocua, at an estimated concentration of $5 \times 10^{8} \mathrm{cells} / \mathrm{ml}$ for $15 \mathrm{~min}$. The sample was rinsed in DI for around $30 \mathrm{~s}$ following which the sample were gently shaken in a solution of $0.05 \%$ Tween-20 in PBS for 5 min. Following a short rinsing step in DI, the cantilever beams were again treated in increasing concentration of methanol in PBS before being dried using a critical point dryer. The resonant frequency was then measured in order to determine the change in resonant frequency due to the bound cells.

As the resonant frequency of the cantilever beam was measured after both the antibody and BSA were attached to the surface, it was desired to find the separate effects of BSA and antibodies on the resonant frequency due to mass loading. The cantilever beam was initially cleaned to remove all the organics using piranha solution as before and measured to obtain the unloaded resonant frequency. The cantilever was then treated with BSA for around 15 min, rinsed in DI for around $30 \mathrm{~s}$, and measured to obtain the loaded resonant frequency. The same cantilever was cleaned again in piranha, measured to obtain the unloaded resonant frequency, treated with antibodies, rinsed in DI, and finally, measured to obtain the new loaded resonant frequency.

\section{E. Critical point drying of antibody layers}

A qualitative experiment was conducted in order to gauge the effect of critical point drying on the effectiveness of the antibodies in capturing the bacterial cells. Silicon pieces of size around $8 \mathrm{~mm} \times 8 \mathrm{~mm}$ were used in this experiment. They were treated with piranha solution in order to remove any organics on them, rinsed in DI water, and $\mathrm{N}_{2}$ blown dry. Two of the chips were treated with antibody and BSA while two others, to be used as controls, were not treated at all and left bare. One of the functionalized chips as well as one of the control chips were then immersed in methanol for $5 \mathrm{~min}$ and critically point dried, while the other functionalized and control chips were air dried. All the four chips were then treated in PBS buffer, placed in fluorescein isothiocyanate (FITC) labeled bacterial suspensions of Listeria innocua (conc. of around $5 \times 10^{8}$ cells $/ \mathrm{ml}$ ), rinsed in DI water, following which they were observed under a fluorescent microscope. Finally after excess water on the chips' surfaces was removed by air drying, they were treated in PBS-Tween $(0.05 \%)$ for $5 \mathrm{~min}$, dipped in DI water and were observed again using a fluorescent microscope. 


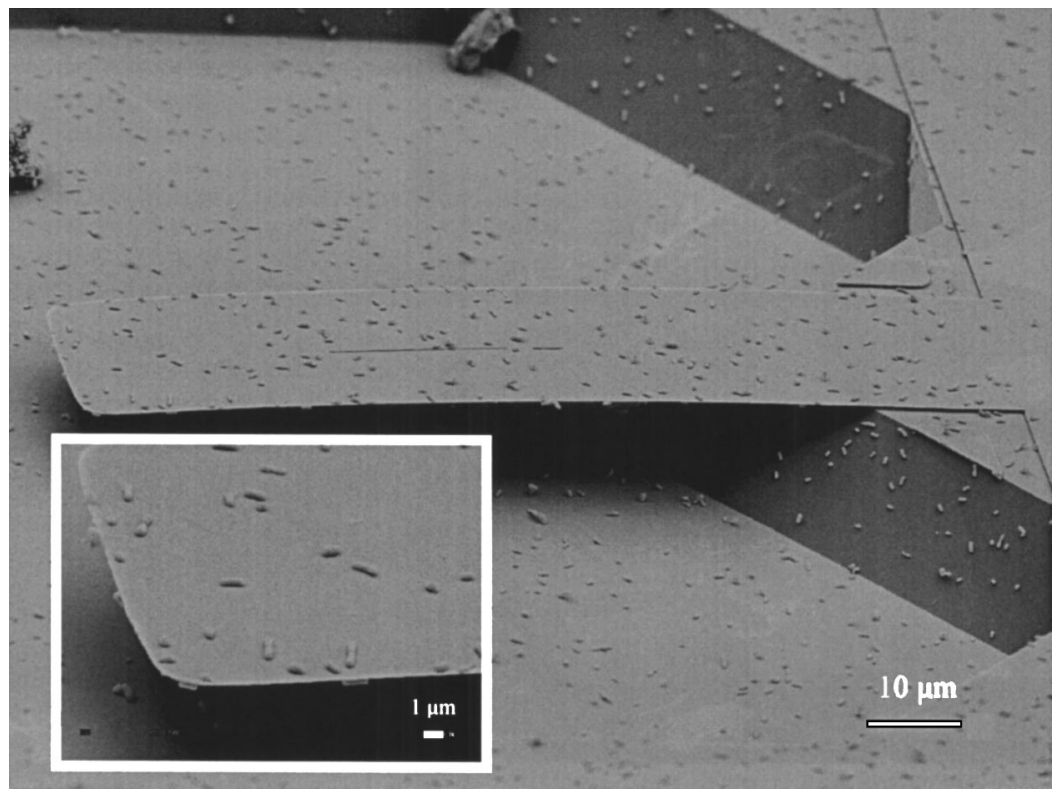

FIG. 2. SEM micrographs showing nonspecific binding of Listeria innocua bacterial cells to cantilever 1 and surrounding area of sample. Inset: Higher magnification view showing the individual bacterial cells.

\section{RESULTS AND DISCUSSION}

\section{A. Detection of bacterial cell mass using nonfunctionalized cantilever beams}

The nonspecific binding experiment was performed in order to see the smallest number of bacterial cells that could be detected with the smallest observable shift in resonant frequency of the cantilever, as well as to test for the linearity of the measurements, thus proving them to be valid. After the last and highest concentration of bacterial cells was introduced on the cantilever beams and the resonant frequency were measured, cantilever 1 was sputtered with a layer of $\mathrm{Au} / \mathrm{Pd}$ and SEM micrographs were taken of the cantilever beam. Figure 2 shows SEM micrographs depicting unselective binding of bacterial cells on cantilever 1. A uniform distribution of the bacterial cells can be seen over the cantilever surface as well as the surrounding area of the sample. The slight bending of the cantilever beams observed in the micrographs is due to the stress caused by the $\mathrm{Au} / \mathrm{Pd}$ layer on top of the cantilever beam.

After each bacterial binding and resonant frequency measurement step, the number of bacterial cells were counted (and doubled to account for the top and bottom surface) from the photomicrographs. The change in mass due to a change in resonant frequency can be given as ${ }^{19}$

$$
\Delta m=\frac{k}{4 n \pi^{2}}\left(\frac{1}{f_{1}^{2}}-\frac{1}{f_{0}^{2}}\right),
$$

where $k$ is the spring constant of the cantilever beam, $f_{0}$ is the initial resonant frequency before the addition of the mass, $f_{1}$ is the resonant frequency after the mass addition, and $n$ $=1$ in the case the added mass is placed right at the free end and $n \sim 0.24$ for the case when the additional mass is uniformly distributed over a rectangular shaped cantilever beam. The assumption is made that the spring constant does not change after the mass addition. Hence, all the values that were obtained for the mass change assumed that all the mass was concentrated at the free end. In order to get a value for the dry cell mass of a single L. innocua bacterium, each of the bacterial cells that were counted on the surface was weighted by a factor of $(x / L)$, where $x$ was the distance from the fixed end and $L$ was the length of the cantilever beam. ${ }^{5}$ As the cells attached nonspecifically over the entire cantilever beam and as it was not possible to count the cells on the bottom of the cantilever it was estimated that the same number of cells attached at the bottom as on the top. Making this assumption and taking an average of the dry cell mass obtained for the three increasing concentrations from different cantilever beams, the dry cell weight was estimated to be around $85 \mathrm{fg}$. Figure 3(a) shows the frequency shift as a function of effective number of bacterial cells bound on surface of cantilever beams with around the same frequency range. Figure 3(b) shows the vibration spectra measured for cantilever 1 before and after binding of around 180 bacterial cells. The resonant frequency shift was close to $1 \mathrm{kHz}$.

The typical shape of Listeria bacteria is cylindrical with dimensions of length around $0.5-2 \mu \mathrm{m}$ and width of around $0.4-0.6 \mu \mathrm{m}$. Assuming that the density of a bacterial cell is slightly higher than that of water $\left(\sim 1.05 \mathrm{~g} / \mathrm{cm}^{3}\right)$ with length of $2 \mu \mathrm{m}$ and width of $0.4 \mu \mathrm{m}$, and that around $70 \%$ of the cell mass is due to water, calculations show the dry cell mass is expected to be around $79 \mathrm{fg}$. This is certainly close to the measured range of around $85 \mathrm{fg}$. Ultrasensitive cantilever beams that can detect single cells can be achieved by scaling down the planar dimensions of the cantilever beams, ${ }^{3,5}$ with a proportionate decrease in the thickness of the cantilever beams in order to decrease the bandwidth of the cantilever beams. The sensitivity of the resonators can also be increased by improving the quality factor $(Q)$ of the cantilever beams, which can be achieved by externally driving the cantilevers, performing the measurement in vacuum and the like. 
Ferquency Shift vs. No. of Cells

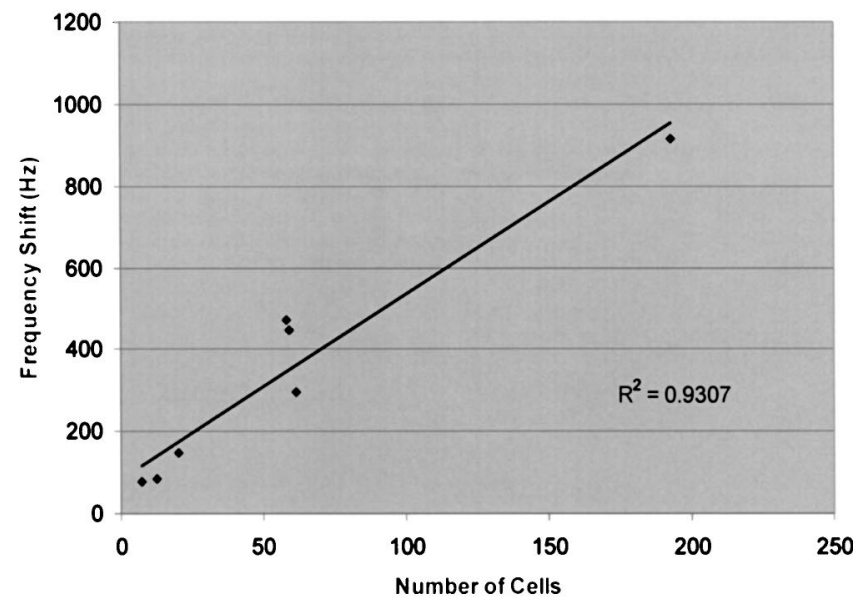

(a)

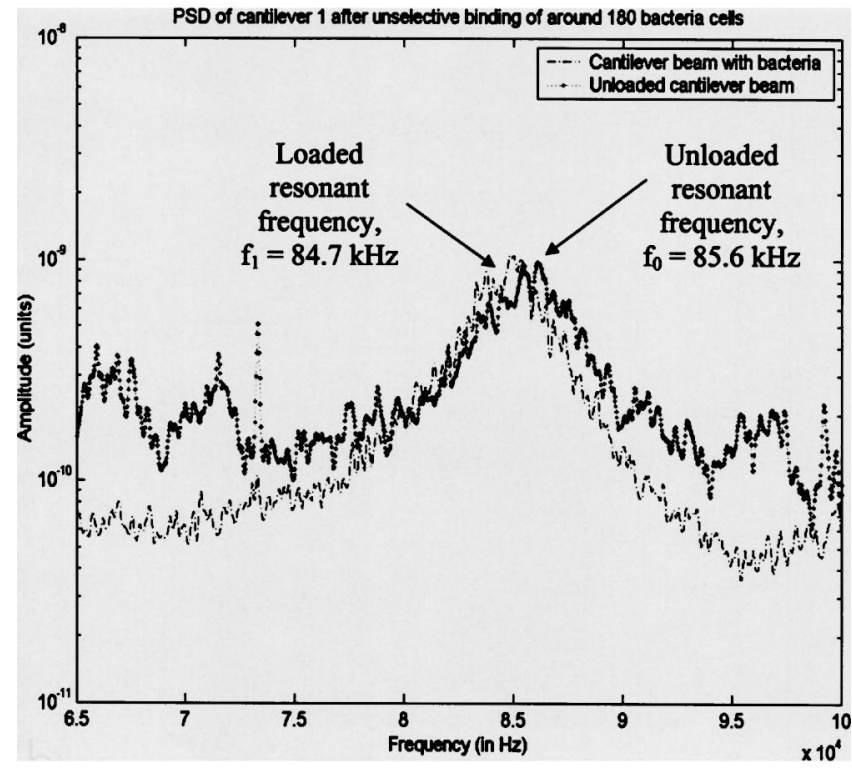

(b)

FIG. 3. (a) Measured resonant frequency shift versus effective number of Listeria innocua bacterial cells binding to cantilever 1. (b) Resonant frequency measurement before (-.) and after (.:) bacterial cell binding on cantilever beam 1 . The values of resonant frequencies are extracted from fitting the measured curves to Eq. (1) (the fitted curves are not shown).

\section{B. Detection of bacterial cell mass using antibody-coated cantilever beams}

Cantilever beam 2 was used to measure the mass of the adsorbed antibodies and BSA, followed by the mass of the bacterial cells along with the protein layer. Figure 4 shows the change in resonant frequency of cantilever 2 at different stages of the experiment of selectively capturing bacterial cells on the cantilever. The resonant frequency was measured after a piranha clean of the cantilever beams, after the antibody plus BSA immobilization, and finally after the bacterial introduction. It should be pointed out that each of the steps was followed by a critical point drying step as the resonant frequency needed to be measured in air. As stated before, the

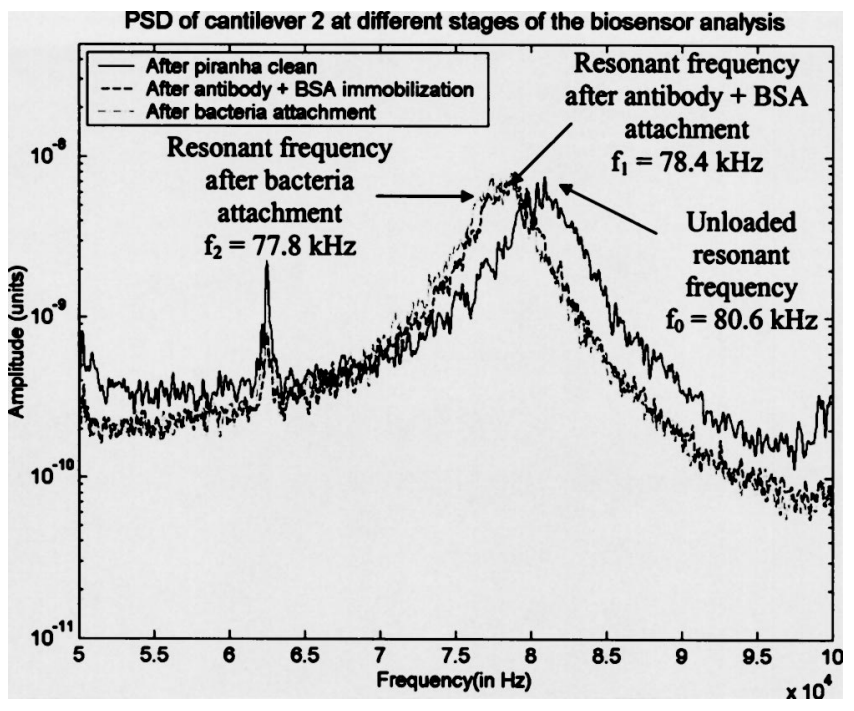

FIG. 4. Resonant frequency measurement showing unloaded cantilever beam (-), after antibody + BSA immobilization (--) and after bacterial cell binding (-.) on cantilever beam 2. The values of resonant frequencies are extracted from fitting the measured curves to Eq. (1) (the fitted curves are not shown).

critical point drying was done in order to avoid the stiction problem that normally occurs for surface micromachined structures after being pulled from a liquid medium.

The largest frequency change was measured after the antibody plus BSA immobilization step which was about 2 $\mathrm{kHz}$. Using Eq. (3) and assuming that the antibody and BSA form a uniform layer over the cantilever beam surface, the added mass was calculated to be around $93 \mathrm{pg}$ for cantilever 2. The cantilevers were not bent indicating that the adsorption was on both sides of the cantilever. There was a shift in resonant frequency of around $500 \mathrm{~Hz}$ (corresponding to a mass change of $5.3 \mathrm{pg}$ ) after the attachment of the bacterial cells, as shown in Fig. 4. The effective number of bacterial cells that were captured on cantilever 2 was estimated to be around 62 bacterial cells (assuming the mass of each bacterial cell to be around $85 \mathrm{fg}$ ).

The mass of the antibody and BSA layer that was adsorbed on the cantilever beam surface was measured to be around $90 \mathrm{pg}$. In order to estimate whether the values were reasonable, one can make some rough calculations. The molecular weight of an antibody molecule (IgG) is estimated to be around $150 \mathrm{kDa},{ }^{20}$ with an effective area for a single molecule to be around $45 \mathrm{~nm}^{2}$. The molecular weight of a BSA molecule is around $66 \mathrm{kDa}$ with an effective area of around $44 \mathrm{~nm}^{2}$ (assuming BSA to be an ellipsoid with dimensions of $14 \mathrm{~nm}$ by $4 \mathrm{~nm}) .{ }^{21}$ Since the antibody was first attached to the cantilever beam, followed by BSA, it is safe to assume that the BSA covers only those areas not covered by the antibody itself and that they do not attach to the antibody layer. It should be reasonable to assume that the antibodies cover the majority of the surface area of the cantilever beam. Assuming total coverage over the entire cantilever surface area (top and bottom of the cantilever) by the antibody, a mass of around $87 \mathrm{pg}$ (mass of antibody layer divided by 0.24 ) is calculated. Since the antibodies and BSA are non- 


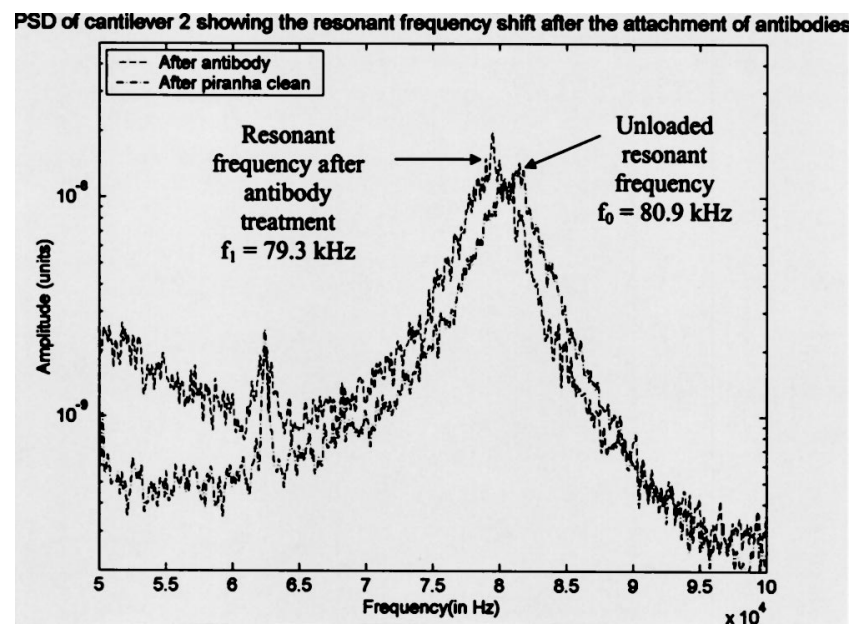

FIG. 5. Resonant frequency shift after the attachment of the antibody to Listeria innocua to cantilever beam 2. The values of resonant frequencies are extracted from fitting the measured curves to Eq. (1) (the fitted curves are not shown).

specifically adsorbed, they will be randomly attached to the cantilever and could also be attached in multiple layers. The measured values of added mass are, however, in the expected pg range.

In order to better ascertain the effect of mass loading, by BSA and the antibody, on the resonant frequency, they were separately attached to the cantilever beam and the resonant frequency shift was measured. The antibody (conc. of $1 \mathrm{mg} / \mathrm{ml}$ ) gave a frequency shift of around $1.48 \mathrm{kHz}$, which corresponds to a mass change of $59 \mathrm{pg}$ (see Fig. 5). BSA (conc. of $2 \mathrm{mg} / \mathrm{ml}$ ) gave a frequency change of around 3.94 $\mathrm{kHz}$ which corresponds to a mass change of around $166 \mathrm{pg}$ (see Fig. 6). In the case of BSA, theoretical calculations give an expected value of around $40 \mathrm{pg}$, when making the same

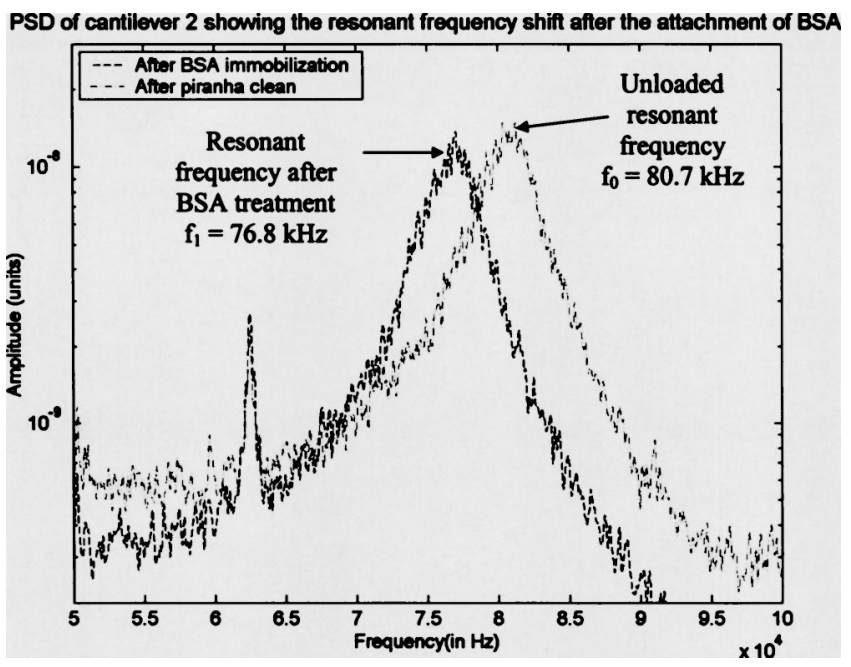

FIG. 6. Resonant frequency shift after the attachment of BSA to cantilever beam 2 .

assumptions as were made in the case for the antibody. One possible reason for the difference could be that the BSA molecules are stacking on top of each other forming multiple layers.

\section{Effectiveness of antibodies after critical point drying}

Critical point drying was done before many resonant frequency measurement steps, so as to minimize stiction of the cantilever beams to the underlying substrate. Figure 7 shows fluorescent photomicrographs taken after all the samples (see Sec. II E) with the bacteria were treated in PBS-Tween $(0.05 \%)$ for $5 \mathrm{~min}$ and rinsed in DI water, and were taken at a magnification of $400 \times$. Figure 7 (a) shows the sample with
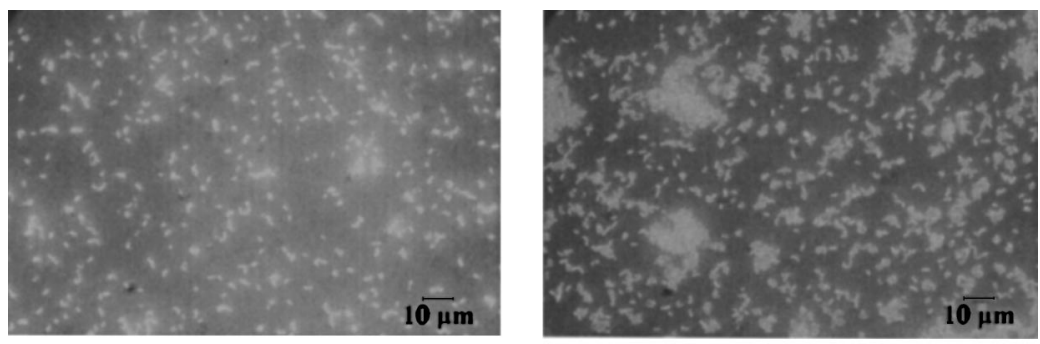

(a)

(b)
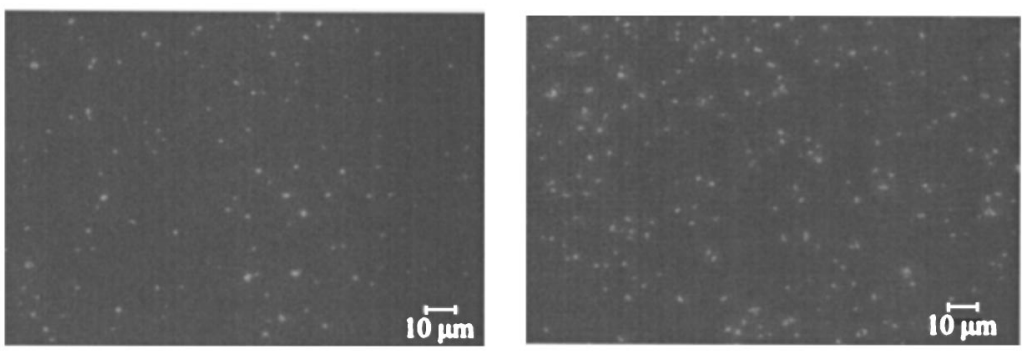

(c)

(d)
FIG. 7. (a) Photomicrograph showing a sample with antibody and BSA that were not dried with CPD. (b) Photomicrograph of sample with antibody and BSA that was dried using CPD. (c) Control sample with no antibody and no BSA and that was air dried. (d) Control sample with no antibody and no BSA that was dried with CPD. (Note: The magnifications of all the photomicrographs were at $400 \times$.) 
attached antibodies and BSA that had been air dried. Figure 7(b) shows the sample with the antibody and BSA that had been dried using CPD. Figures 7(c) and 7(d) show the control sample with no antibody and no BSA was attached, with the sample shown in Fig. 7(c) on which no CPD was performed, and the sample shown in Fig. 7(d) on which CPD was performed. Comparing all the photomicrographs, lead us to some general conclusions. CPD does not adversely affect the ability of the antibody to capture the bacterial cells. Inspecting the photomicrographs of the controls, we see that the CPD dried sample as well as the sample on which no CPD was performed, captured significantly less bacterial cells than the samples with the antibody-functionalized surfaces. More analysis is needed to study this effect in detail but our experiments demonstrated qualitatively that performing CPD step once on the antibodies does not denature or damage them appreciably.

\section{CONCLUSIONS}

The present study demonstrated the use of a novel surface micromachined cantilever beams as a resonant mass sensor for biological applications. This work showed that the present technique and devices can be used to measure the mass of adsorbed proteins and to perform rapid and sensitive detection of bacterial cells. Antigen-antibody interactions were used to capture bacterial cells on functionalized surfaces, hence paving the way for an immunospecific resonant mass sensor based on surface micromachined cantilever beams.

\section{ACKNOWLEDGMENTS}

The authors would like to thank T. Miller, D. Lubelski, and W. Crabill of the microfabrication laboratories of Purdue University for their valuable technical assistance, Professor A. Bhunia and his laboratory in the Department of Food Science, Purdue University for providing bacteria used in this study, Debby Sherman of the Microscopy Center in School of Agriculture, Purdue University for taking the SEM micrographs of the cantilevers with bacteria attached, R. Gómez for his help with the bacterial growth, and T. Huang for his helpful comments. This work was supported by National Science Foundation (NSF Career Award No. ECS9984199).

${ }^{1}$ G. Binnig, C. F. Quate, and Ch. Gerber, Phys. Rev. Lett. 56, 930 (1986). ${ }^{2}$ R. Raiteri, M. Grattarola, H.-J. Butt, and P. Skládal, Sens. Actuators B 79, 115 (2001).

${ }^{3}$ B. Ilic, D. Czaplewski, H. G. Craighead, P. Neuzil, C. Campagnolo, and C. Batt, Appl. Phys. Lett. 77, 450 (2000).

${ }^{4}$ A. Gupta, D. Akin, and R. Bashir, Microfluidics, BioMEMS, And Medical Microsystems Conference, SPIE Photonics West Micromachining And Microfabrication 2003 Symposium, 4982, January 2003, San Jose, CA.

${ }^{5}$ B. Ilic, D. Czaplewski, M. Zalalutdinov, H. G. Craighead, P. Neuzil, C. Campagnolo, and C. Batt, J. Vac. Sci. Technol. B 19, 2825 (2001).

${ }^{6}$ P. E. Andreotti, G. V. Ludwig, A. H. Peruski, J. J. Tuite, S. S. Morse, and L. F. Peruski, Jr., BioTechniques 35, 850 (2003).

${ }^{7}$ D. Ivnitski, D. J. O'Neil, A. Gattuso, R. Schlicht, M. Calidonna, and R. Fisher, BioTechniques 35, 862 (2003).

${ }^{8}$ G. Stemme, J. Micromech. Microeng. 1, 113 (1991).

${ }^{9}$ A. Gupta, J. Denton, H. McNally, and R. Bashir, J. Microelectromech. Syst. 12, 185 (2003)

${ }^{10}$ J. L. Glenn, Jr., G. W. Neudeck, C. K. Subramanian, and J. P. Denton, Appl. Phys. Lett. 60, 483 (1992).

${ }^{11}$ J. J. Pak, A. E. Kabir, G. W. Neudeck, and J. H. Logsdon, Sens. Actuators, A 56, 267 (1996).

${ }^{12}$ J. Yang, T. Ono, and M. Esashi, Sens. Actuators, A 82, 102 (2000)

${ }^{13}$ D. Saya, K. Fukushima, H. Toshiyoshi, G. Hashiguchi, H. Fujita, and H. Kawakatsu, Sens. Actuators, A 95, 281 (2002).

${ }^{14}$ D. A. Walters, J. P. Cleveland, N. H. Thomson, P. K. Hansma, M. A. Wendman, G. Gurley, and V. Elings, Rev. Sci. Instrum. 67, 3583 (1996).

${ }^{15}$ J. P. Cleveland, S. Manne, D. Bocek, and P. K. Hansma, Rev. Sci. Instrum. 64, 403 (1993).

${ }^{16}$ Y. Martin, C. C. Williams, and H. K. Wickramasinghe, J. Appl. Phys. 61, 4723 (1987).

${ }^{17}$ T. R. Albrecht, P. Grütter, D. Horne, and D. Rugar, J. Appl. Phys. 69, 668 (1991).

${ }^{18}$ T. T. Huang, J. Sturgis, R. Gomez, T. Geng, R. Bashir, A. K. Bhunia, J. P. Robinson, and M. R. Ladisch, Biotechnol. Bioeng. 81, 618 (2003).

${ }^{19}$ G. Y. Chen, T. Thundat, E. A. Wachter, and R. J. Warmack, J. Appl. Phys. 77, 3618 (1995).

${ }^{20}$ L. Stryer, Biochemistry (Freeman, New York, 1995).

${ }^{21}$ T. Peters, Jr., Advances in Protein Chemistry, edited by C. B. Anfinsen, J. T. Edsall, and F. M. Richards (Academic, New York, 1985), Vol. 37, pp. $161-245$. 